[1] R. H. Baughman, A. A. Zakhidov, W. A. de Heer, Science 2002, 297, 787.

[2] R. Andrews, D. Jacques, A. M. Rao, T. Rantell, F. Derbyshire, Y. Chen, J. Chen, R. C. Haddon, Appl. Phys. Lett. 1999, 75, 1329.

[3] a) M. S. P. Shaffer, A. H. Windle, Adv. Mater. 1999, 11, 937. b) X.-Y. Gong, J. Liu, S. Baskaran, R. D. Voise, J. S. Young, Chem. Mater. 2000, 12, 1049. c) Z.-X. Jin, K. P. Pramoda, G.-Q. Xu, S. H. Goh, Chem. Phys. Lett. 2001, 337, 43.

[4] S. Kumar, T. D. Dang, F. E. Arnold, A. R. Bhattacharyya, B. G. Min, X.-F. Zhang, R. A. Vaia, C. Park, W. W. Adams, R. H. Hauge, R. E. Smalley, S. Ramesh, P. A. Willis, Macromolecules 2002, 35, 9039.

[5] X. Zhang, T. Liu, T. V. Sreekumar, S. Kumar, V. C. Moore, R. H. Hauge, R. E. Smalley, Nano Lett. 2003, 3, 1285.

[6] J. C. Masson, Acrylic Fiber Technology and Applications, Marcel Dekker, New York 1995

[7] W. Watt, in Strong Fibers (Eds: W. Watt, B. V. Perov), North-Holland, Amsterdam 1985, Ch. 9.

[8] T. Kowalewski, N. V. Tsarevsky, K. Matyjaszewski, J. Am. Chem. Soc. 2002, 124, 10632 .

[9] C. Pirlot, I. Willems, A. Fonseca, J. B. Nagy, J. Delhalle, Adv. Eng. Mater. 2002, 4, 109

[10] a) K. D. Ausman, R. Piner, O. Lourie, R. S. Ruoff, M. Korobov, J. Phys. Chem. B 2000, 104, 8911. b) J. L. Bahr, E. T. Mickelson, M. J. Bronikowski, R. E. Smalley, J. M. Tour, Chem. Commun. 2001, 2, 193.

[11] T. Liu, T. V. Sreekumar, S. Kumar, R. H. Hauge, R. E. Smalley, Carbon 2003, 41, 2440.

[12] J. Zeng, B. Saltysiak, W. S. Johnson, D. A. Schiraldi, S. Kumar, Composites, Part $B$, in press.

[13] B. D. Cullity, Elements of X-Ray Diffraction, 2nd ed., Addison-Wesley Publishing Company, Reading, MA 1978, p. 102.

[14] R. J. Samuels, Structured Polymer Properties: The Identification, Interpretation, and Application of Crystalline Polymer Structure, John Wiley \& Sons, New York 1974.

[15] M. L. Dunn, H. L. Ledbetter, P. R. Heyliger, C. S. Choi, J. Mech. Phys. Solids 1996, 44, 1509.

[16] T. Liu, S. Kumar, Nano Lett. 2003, 3, 647 .

[17] T. Uchida, T. V. Sreekumar, T. Lui, S. Kumar, unpublished.

[18] a) P. Nikolaev, M. J. Bronikowski, R. K. Bradley, F. Rohmund, D. T. Colbert, K. A. Smith, R. E. Smalley, Chem. Phys. Lett. 1999, 313, 91. b) I. W. Chiang, B. E. Brinson, R. E. Samlley, J. L. Margrave, R. H. Hauge, J. Phys. Chem. B 2001, 105, 1157.

[19] a) R. Haggenmueller, H. H. Gommans, A. G. Rinzler, J. E. Fischer, K. I. Winey, Chem. Phys. Lett. 2000, 330, 219. b) J. Hwang, H. H. Gommans, A. Ugawa, H. Tashiro, R. Haggenmueller, K. I. Winey, J. E. Fischer, D. B. Tanner, A. Rinzler, Phys. Rev. B 2000, 62, 13310. c) H. H. Gommans, J. W. Alldredge, H. Tashiro, J. Park, J. Magnuson, A. G. Rinzler, J. Appl. Phys. 2000, 88, 2509. d) J. E. Fischer, W. Zhou, J. Vavro, M. C. Llaguno, C. Guthy, R. Haggenmueller, M. J. Casavant, D. E. Walters, R. E. Smalley, J. Appl. Phys. 2003, 93, 2157.

[20] T. Liu, S. Kumar, Chem. Phys. Lett. 2003, 378, 257.

\section{Efficient Organic Blue-Light-Emitting Devices with Double Confinement on Terfluorenes with Ambipolar Carrier Transport Properties**}

\section{By Chung-Chih Wu,* Yu-Ting Lin, Ken-Tsung Wong,*} Ruei-Tang Chen, and Yuh-Yih Chien

Organic light-emitting devices (OLEDs) have been the subject of intense investigation in recent years due to their applications in displays and lighting. ${ }^{[1-3]}$ In all these applications, good blue-emitting materials and devices have been essential and therefore there have been continual efforts towards exploring blue-emitting materials and devices with improved characteristics. ${ }^{[4-13]}$

Among various blue-emitting materials reported, fluorenebased polymers or compounds have attracted wide interest in recent years as efficient blue emitters. ${ }^{[14-20]}$ In our previous studies we have found that ter(9,9-diarylfluorene)s (TDAFs) 1 and 2 (Fig. 1) exhibit some intriguing properties that are promising for blue-light-emitting devices. ${ }^{[21,22]}$ The C9-aryl

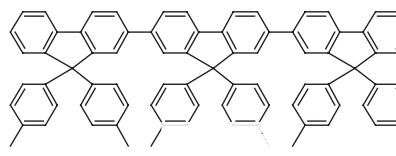

TDAF 1

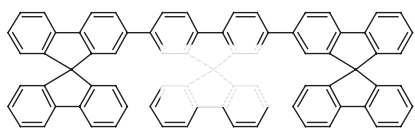

TDAF 2

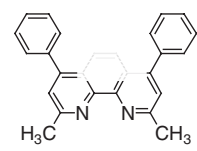

BCP

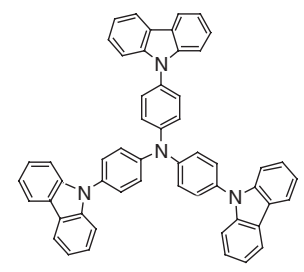

TCTA

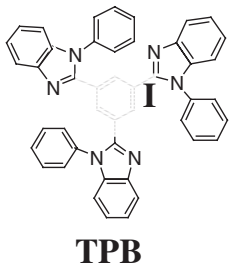

Figure 1. Chemical structures of various compounds used: TDAF 1 and 2, TCTA, TPBI, BCP.

[**] Prof. C.-C. Wu, Y.-T. Lin Department of Electrical Engineering Graduate Institute of Electro-optical Engineering and Graduate Institute of Electronics Engineering National Taiwan University

Taipei 106 (ROC)

E-mail: chungwu@cc.ee.ntu.edu.tw

Prof. K.-T. Wong, R.-T. Chen, Y.-Y. Chien

Department of Chemistry

National Taiwan University

Taipei 106 (ROC)

[**] The authors gratefully acknowledge the financial support from the National Science Council (Grant No. NSC 92-2215-E-002-011, NSC 91-2113 M-002-025) and the Ministry of Education of Republic of China. 
substituents render the molecular structures rather bulky, providing effective hindrance to interchromophore packing. As a consequence, these compounds form stable and homogeneous amorphous films with vacuum deposition, exhibiting high glass-transition temperatures of $>200{ }^{\circ} \mathrm{C}$ and high thin-film photoluminescence (PL) quantum yields of $90 \%$ with pure blue emission. These terfluorenes are electrochemically stable as indicated by both reversible oxidation and reduction. Furthermore, they exhibit unusual nondispersive ambipolar carrier-transport properties with high carrier mobilities on the order of $10^{-3} \mathrm{~cm}^{2} \mathrm{~V}^{-1} \mathrm{~s}^{-1}$ for both holes and electrons. ${ }^{[22]}$ In this paper, we report the investigation of various device architectures employing the unique optical and electrical properties of these terfluorenes and their strong influences on the characteristics of blue OLEDs.

Figure 1 shows the chemical structures of TDAF $\mathbf{1}$ and $\mathbf{2}$, along with some compounds used in this study. 4,4',4"-tri( $N$-carbazolyl)triphenylamine (TCTA) was used as the holetransport layer (HTL) in some device structures, ${ }^{[23]}$ and $2,2^{\prime}, 2^{\prime \prime}-(1,3,5$-benzenetriyl $)$ tris[1-phenyl- $1 H$-benzimidazole] (TPBI) or 2,9-dimethyl-4,7-diphenyl-1,10-phenanthroline (BCP) was used as the electron-transport layer (ETL) in some device structures. ${ }^{[9,24]}$ The energy levels and optical properties of these compounds are summarized in Table 1. The devices were fabricated on glass substrates with the typical structure of multiple organic layers sandwiched between the bottom indium tin oxide (ITO) anode and the top metal cathode. The cathode used consists of a thin LiF layer $(0.5 \mathrm{~nm})$ as the electron injection layer and a thick Al layer as the metal electrode. ${ }^{[25]}$ The stack of organic layers on ITO in sequence consists of a thin layer $(\sim 30 \mathrm{~nm})$ of conducting polymer poly(ethylene dioxythiophene)/poly(styrene sulphonate)
Table 1. The energy levels and optical properties of various compounds in thin films.

\begin{tabular}{cccccc}
\hline Compound & $\mathbf{1}$ & $\mathbf{2}$ & TCTA & TPBI & BCP \\
\hline$\lambda_{\text {max, abs }}[\mathrm{a}]$ & 350 & 350 & 300 & 305 & 282 \\
$\lambda_{\text {onset, abs }}[\mathrm{b}]$ & 405 & 405 & 375 & 360 & 345 \\
$\lambda_{\text {max, }}[\mathrm{c}]$ & 405,430 & 405,430 & 390 & 385 & 403 \\
$E_{\mathrm{g}}[\mathrm{d}]$ & 3.06 & 3.06 & 3.3 & 3.4 & 3.6 \\
$I_{\mathrm{p}}[\mathrm{e}]$ & $5.4 \sim 5.5$ & $\sim 5.6$ & $5.5 \sim 5.6$ & $\geq 6.2$ & $\geq 6.2$ \\
EA [f] & $2.34 \sim 2.44$ & $\sim 2.54$ & $2.2 \sim 2.3$ & $\leq 2.8$ & $\leq 2.6$ \\
\hline
\end{tabular}

[a] First absorption peak [nm]. [b] Absorption onset [nm]. [c] Photoluminescence peak [nm]. [d] Optical energy gap determined from the absorption onset [eV]. [e] Ionization potential [eV]. [f] Electron affinity [eV].

(PEDT:PSS, Bayer Corp.) as the hole injection layer ${ }^{[26]}$ and other functional layers of low molecular weight. Various devices architectures studied are listed below, in which the type of TDAF used is indicated by the number:

S-1, S-2: ITO/PEDT:PSS/TDAF 1 or $2(100 \mathrm{~nm}) / \mathrm{LiF} / \mathrm{Al}$

DI-1, DI-2: ITO/PEDT:PSS/TCTA $(50 \mathrm{~nm}) / \mathrm{TDAF} \mathbf{1}$ or $\mathbf{2}$ $(50 \mathrm{~nm}) / \mathrm{LiF} / \mathrm{Al}$

DII-1, DII-2: ITO/PEDT:PSS/TDAF 1 or $2(50 \mathrm{~nm}) / \mathrm{TPBI}$ $(50 \mathrm{~nm}) / \mathrm{LiF} / \mathrm{Al}$

T-1, T-2: ITO/PEDT:PSS/TCTA $(40 \mathrm{~nm}) / \mathrm{TDAF} \mathbf{1}$ or $\mathbf{2}$ $(30 \mathrm{~nm}) / \mathrm{TPBI}(30 \mathrm{~nm}) / \mathrm{LiF} / \mathrm{Al}$

Considering the ambipolar nature of the present terfluorenes, we first explored the device architecture comprising only a single layer of TDAF sandwiched between the hole-injection contact and the electron-injection contact (i.e., devices S-1 and S-2). Such single-layer devices exhibit pure blue electroluminescence (EL) from terfluorenes, however, with a low quantum efficiency of only $\sim 0.15 \%$ photon/electron (Fig. 2).
Figure 2. a) Brightness-voltage, and b) efficiency-current density characteristics of devices incorporating TDAF 1. c) Brightness-voltage, and d) efficiencycurrent density characteristics of devices incorporating TDAF 2. (a)

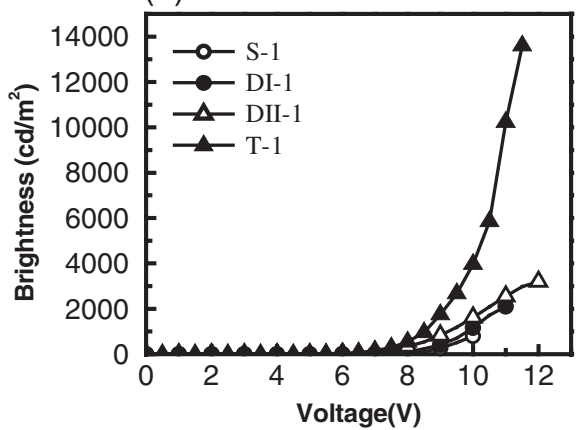

(c)

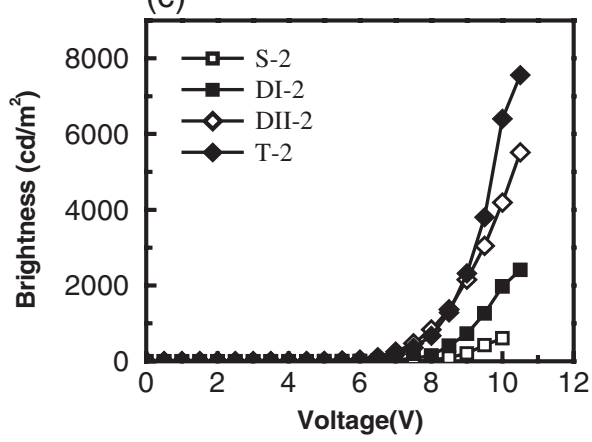

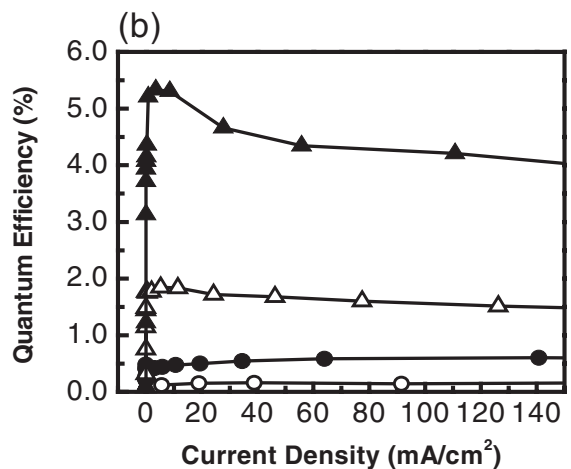

(d)

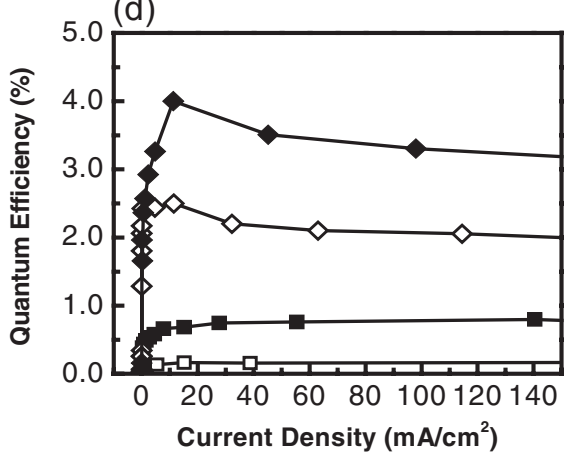


In view of their very high PL efficiencies, low EL efficiencies suggest poor balance of hole and electron currents and/or poor confinement of carriers and excitons in the devices. Therefore, even though the present terfluorenes possess ambipolar transport properties, heterostructures may still be a necessity for enhancing device performance. More advanced heterostructure devices employing the TDAF as HTL in combination with another ETL, or employing the TDAF as the ETL in combination with another HTL, were then investigated.

For devices containing the HTL/TDAF heterostructure, initial experiments using the widely used $\alpha$-NPD $\left(4,4^{\prime}\right.$-bis $[N$ - $(1-$ naphyl)- $N$-phenyl-amino] biphenylas) HTL gave emission from $\alpha$-NPD instead of the desired terfluorene, indicating that the terfluorene acts as a hole-blocking and electron-transport material for $\alpha$-NPD. Replacing $\alpha$-NPD with TCTA (i.e., devices DI-1 and DI-2), which has a larger ionization potential $\left(I_{\mathrm{p}}\right)$, a larger energy gap, and a smaller electron affinity (EA) than $\alpha$-NPD, successfully achieved injection of holes into and confinement of electrons within the terfluorenes, rendering EL purely from terfluorenes. As shown in Figure 2, both the EL quantum efficiencies (0.6-0.8\%) and brightnesses are substantially enhanced in comparison with preceding single-layer devices, indicating the effect of TCTA on better balancing hole/electron currents.

For devices containing the TDAF/ETL heterostructure, initially the widely used electron-transport material $\mathrm{Alq}_{3}$ (aluminum tris(8-hydroxy-quinoline)) was used as the ETL. EL efficiencies and brightnesses were also enhanced compared to single-layer devices, however, with green emission purely from $\mathrm{Alq}_{3}$. Such results indicate that injected electrons are effectively confined in $\mathrm{Alq}_{3}$ presumably due to the substantial energy offset for electrons at the terfluorene/ $/ \mathrm{Alq}_{3}$ interface while holes can be injected into $\mathrm{Alq}_{3}$ from the terfluorene. Replacing $\mathrm{Alq}_{3}$ with TPBI (i.e., devices DII-1 and DII-2), an electron-transport material that has a larger $I_{\mathrm{p}}$, a larger energy gap, and a smaller EA than $\mathrm{Alq}_{3}$, accomplished injection of electrons into and confinement of holes within terfluorenes, rendering the EL purely from terfluorenes. In comparison with single-layer devices discussed earlier (Fig. 2), these devices also exhibit substantially enhanced quantum efficiencies (1.8 \% for DII-1, 2.5 \% for DII-2) and brightnesses, indicating the effectiveness of TPBI on better balancing hole/electron currents of devices.

In the preceding TCTA/TDAF and TDAF/TPBI heterostructure devices, one type of carrier (electrons in the TCTA/ TDAF structure, or holes in the TDAF/TPBI structure) is effectively confined in TDAF due to the existence of the energy offset or the carrier-mobility offset inherent with the heterostructure. However, the other type of carrier (holes in the TCTA/TDAF structure, or electrons in the TDAF/TPBI structure), when injected into the TDAF, may travel deep into the TDAF before recombination and may not be effectively confined near the junction due to the ambipolar carrier-transport nature of TDAFs. The consequences may be manifold. First, some carriers may travel through without recombination. Sec- ond, the recombination zone may be broadly distributed in the TDAF, with a substantial portion of it in the proximity of the electrodes and subject to electrode quenching of luminescence. ${ }^{[27-29]}$ All these situations, if occurring, are detrimental to the efficiency of devices. As an indication, the observed EL quantum efficiencies for the preceding double-layer devices are apparently lower than one would expect from very high thin-film PL quantum yields of TDAFs, assuming balanced hole/electron currents and ideal carrier recombination.

In view of these considerations, a more advanced device structure with the TCTA/TDAF/TPBI double heterostructure, i.e., devices T-1 and T-2, was investigated. Such structure makes use of the capability of TCTA in blocking electrons and the capability of TPBI in blocking holes. In addition, TCTA and TPBI have the further advantage of confining excitons within the TDAF since both TCTA and TPBI have larger energy gaps ( $3.3 \mathrm{eV}$ for TCTA, $3.4 \mathrm{eV}$ for TPBI) than the present TDAFs $(3.06 \mathrm{eV})$. Such exciton confinement could hinder excitons from diffusing towards electrodes or transferring energy to neighboring charge-transport layers with lower-energy emission and/or less efficient luminescence, beneficial to device efficiency and color purity.

The double heterostructure devices exhibit pure blue EL from TDAFs and high EL quantum efficiencies of $5.3 \%$ $\left(1.53 \mathrm{~cd} \mathrm{~A}^{-1}\right)$ for $\mathbf{T}-1$ and $4.1 \%\left(1.1 \mathrm{~cd} \mathrm{~A}^{-1}\right)$ for T-2 (Fig. 2). High brightnesses of $\sim 14000$ and $\sim 8000 \mathrm{~cd} \mathrm{~m}^{-2}$ are obtained for T-1 and T-2, respectively (Fig. 2). Such high EL efficiencies are more consistent with the high PL quantum yields of TDAFs and indicate the effectiveness of the present double heterostructure on better confinement of carriers and excitons. In view of the fact that the blue-light-emitting layer is non-doped, these EL efficiencies are very high for pure blue OLEDs, competitive with the best of the doped blue OLEDs. ${ }^{[4,6,7,9]}$ Furthermore, as shown in Figure 3, these devices exhibit rather low turn-on voltage of $\sim 2.5 \mathrm{~V}$ (as defined as the voltage where emission becomes detectable). Such low turn-on voltage is also rare for blue OLEDs, which in nature incorporate large-bandgap materials in the device and usually render larger difficulty in achieving low voltage. ${ }^{[7,9]}$ These devices exhibit saturated blue emission with 1931 CIE (Commission Internationale de l'Eclairage) coordinates of $(0.158$,

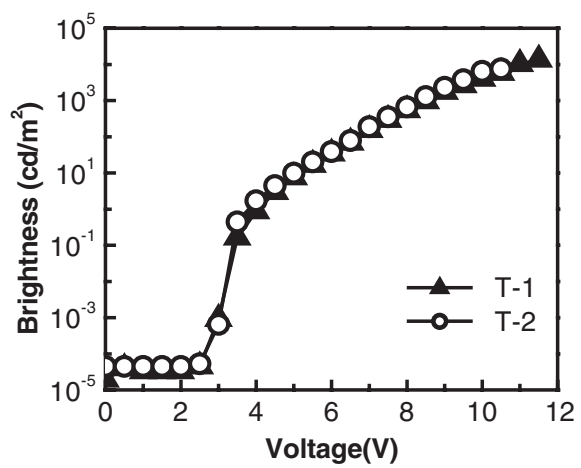

Figure 3. Brightness-voltage characteristics of devices T-1 and T-2 in the semi-logarithmic scale. 
$0.041)$ and $(0.160,0.044)$ for T-1 and T-2, respectively (Fig. 4 and its inset). These values are beyond the NTSC (National Television Standards Committee) blue standard and may give an enlarged color gamut for color displays. Finally, it is worth mentioning that double-heterostructure devices using another large-energy-gap ETL BCP (i.e., TCTA/TDAF/BCP structures) also give blue EL performances (efficiency and brightness) similar to those of TCTA/TDAF/TPBI devices, except for slightly higher operation voltages.

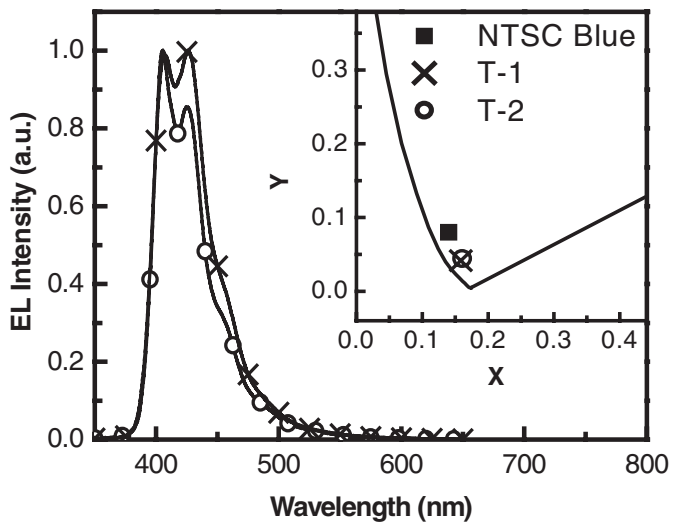

Figure 4. EL spectra of devices T-1 and T-2. Inset: $1931 \mathrm{CIE}$ coordinates of devices T-1 and T-2, along with the NTSC blue standard. The full widths at half maxima (FWHM) of EL spectra are $49 \mathrm{~nm}$ and $44 \mathrm{~nm}$ for T-1 and T-2, respectively.

The demonstration of double-heterostructure OLEDs that provides effective confinement on both types of carriers and excitons was first reported by Adachi et al. for green OLEDs. ${ }^{[30]}$ The application of such device configurations to blue OLEDs, however, is in general more difficult, mainly because of the difficulty in finding appropriate carrier-transport materials to meet many requirements, such as relatively large energy gaps (e.g., >3 eV) for exciton confinement, energy levels matching relatively larger $I_{\mathrm{p}}$ and smaller EA of bluelight-emitting materials for injecting one type of carriers, and yet appropriate carrier-transport properties or energy levels for blocking the opposite type of carriers. As an instance, employing the widely used electron-transport material $\mathrm{Alq}_{3}$ as the ETL for blue OLEDs often leads to partial emission from $\mathrm{Alq}_{3}$ and thus deterioration of color purity of blue EL, mainly due to lack of effective exciton and carrier confinement. ${ }^{[9,31]}$ In this work, the double-heterostructure configuration with effective confinement on both types of carriers and excitons has for the first time been successfully implemented in blue OLEDs through judicious choice and combination of materials.

An issue that has long been of interest with fluorene-based blue emitters is the emergence of red-shifted emission bands and consequently degraded color purity associated with morphological variation or oxidative degradation of materials during annealing or passage of current. ${ }^{[14,16,17,20]}$ Preliminary thermal stressing on TDAF films and electrical stressing on EL devices over extended time (tens of hours) indicate prom- ising characteristics of the present TDAFs in such aspects. As shown in Figure 5, the PL spectra of TDAF films show no changes after annealing at $160^{\circ} \mathrm{C}$, and similarly EL spectra of double-heterostructure devices also remain same after continuous operation.

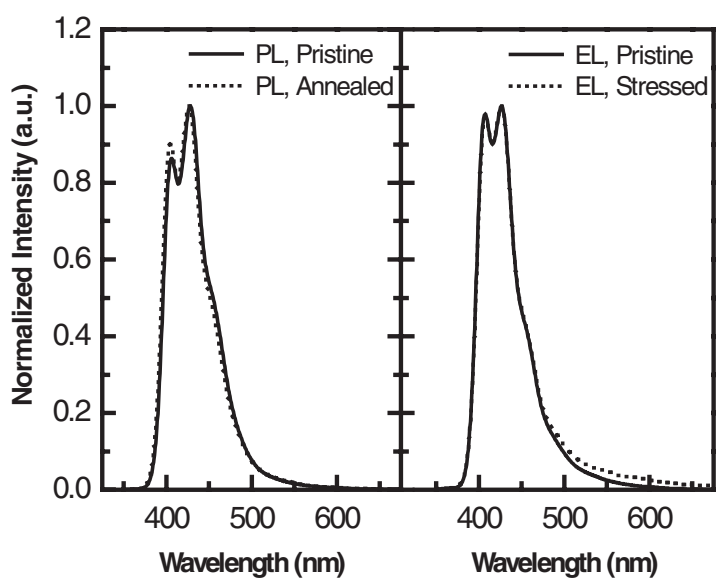

Figure 5. a) Comparison of PL spectra of pristine and annealed $\left(160^{\circ} \mathrm{C}\right.$, $32 \mathrm{~h}$ ) TDAF 1 films, and b) comparison of EL spectra of a pristine and a continuously stressed $\left(7.5 \mathrm{~mA} \mathrm{~cm}^{-2}, 32 \mathrm{~h}\right)$ TDAF 1 double-heterostructure device.

In summary, although TDAFs are capable of bipolar carrier transport, the rather poor device performance of single-layer devices indicates the heterostructure is still essential for achieving high EL efficiencies. In particular, using the double heterostructure that provides effective double confinement on both carriers and excitons results in a highly efficient (5.3\% quantum efficiency), low-voltage ( $2.5 \mathrm{~V}$ turn-on voltage), and color-saturated non-doped blue-light-emitting device. Results of this work have also indicated that device engineering, which bridges promising properties of materials to real device performance, is an essential part of material research, since only through careful device engineering can the potential of a new material be fully explored.

\section{Experimental}

TDAFs investigated in this work were synthesized through the Suzuki coupling reaction of 2,7-diboronic ester of 9,9'-diarylfluorene and 2-bromo-9,9-diarylfluorene in the presence of $\mathrm{Pd}\left(\mathrm{PPh}_{3}\right)_{4}$ and $\mathrm{P}^{t} \mathrm{Bu}_{3}$ catalysts with high yields (75-83\%) as reported previously [21]. Synthesized terfluorenes were subject to purification by temperaturegradient sublimation before use in subsequent studies.

Thin-film samples of organic compounds for optical characterization were prepared by vacuum deposition. The ultraviolet-visible (UV-vis) absorption spectra were measured on a Shimadzu UV1601PC spectrophotometer. PL spectra of thin-film samples were measured by pumping with a monochromatic light taken from a xenon arc lamp and by analyzing with a charge-coupled-device (CCD) spectrograph. The ionization potentials $\left(I_{\mathrm{p}}\right)$ of organic thin films were measured using atmospheric low-energy photoelectron spectrometer Riken-Keiki AC-2 [6,32-34]. The EAs of materials 
were estimated by subtracting the optical energy gap from the measured $I_{\mathrm{p}}$.

OLED devices were fabricated on ITO-coated glass substrates. The PEDT:PSS layer was deposited by spin coating. All other material layers in the devices, including the metal cathode, were deposited by thermal evaporation in a multiple-source vacuum chamber with a base pressure of $<10^{-6}$ torr. The deposition rate of organic layers was kept at about $0.2 \mathrm{~nm} \mathrm{~s}^{-1}$. The deposition system permits the fabrication of the complete device structure in a single vacuum pump-down without breaking vacuum. The active area of the device is $2 \mathrm{~mm} \times 2 \mathrm{~mm}$, as defined by the shadow mask for cathode deposition. The current-voltage-brightness $(I-V-L)$ characteristics of EL devices were measured using a source-measurement unit (SMU) and a $\mathrm{Si}$ photodiode calibrated with Photo Research PR-650 spectroradiometer. The EL spectra were taken with a calibrated CCD spectrograph

Received: July 1, 2003 Final version: October 8, 2003

[1] C. W. Tang, S. A. VanSlyke, Appl. Phys. Lett. 1987, 51, 913.

[2] C. W. Tang, S. A. VanSlyke, C. H. Chen, J. Appl. Phys. 1989, 65, 3610.

[3] F. Steuber, J. Staudigel, M. Stössel, J. Simmerer, A. Winnacker, H. Spreitzer, F. Weissörtel, J. Salbeck, Adv. Mater. 2000, 12, 130.

[4] J. Shi, C. W. Tang, Appl. Phys. Lett. 2002, 80, 3201.

[5] Y.-H. Kim, D.-C. Shin, S.-H. Kim, C.-H. Ko, H.-S. Yu, Y.-S. Chae, S.-K. Kwon, Adv. Mater. 2001, 13, 1690.

[6] C.-C. Wu, Y.-T. Lin, H.-H. Chiang, T.-Y. Cho, C.-W. Chen, K.-T. Wong, Y.-L. Liao, G.-H. Lee, S.-M. Peng, Appl. Phys. Lett. 2002, 81, 577.

[7] C. Hosokawa, H. Higashi, H. Nakamura, T. Kusumoto, Appl. Phys. Lett. 1995, 67, 3853.

[8] Y. Kijima, N. Asai, S.-I. Tamura, Jpn. J. Appl. Phys. 1999, 38, 5274.

[9] Y. Li, M. K. Fung, Z. Xie, S.-T. Lee, L.-S. Hung, J. Shi, Adv. Mater. 2002, 14, 1317.

[10] L.-H. Chan, H.-C. Yeh, C.-T. Chen, Adv. Mater. 2001, 13, 1637.

[11] H.-T. Shih, C.-H. Lin, H.-H. Shih, C.-H. Cheng, Adv. Mater. 2002, 14, 1409.

[12] F. Steuber, J. Staudigel, M. Stossel, J. Simmerer, A. Winnacker, H. Spreitzer, F. Weissortel, J. Salbeck, Adv. Mater. 2000, 12, 130 .

[13] H. Spreitzer, H. Schenk, J. Salbeck, F. Weissortel, H. Riel, W. Riess, Proc. SPIE-Int. Soc. Opt. Eng. 1999, 3797, 316.

[14] U. Scherf, E. J. W. List, Adv. Mater. 2002, 14, 477.

[15] K.-H. Weinfurtner, F. Weissortel, G. Harmgarth, J. Salbeck, Proc. SPIE-Int. Soc. Opt. Eng. 1998, 3476, 40.

[16] D. Katsis, Y. H. Geng, J. J. Ou, S. W. Culligan, A. Trajkovska, S. H. Chen, L. J. Rothberg, Chem. Mater. 2002, 14, 1332.

[17] Y. Geng, D. Katsis, S. W. Culligan, J. J. Ou, S. H. Chen, L. J. Rothberg, Chem. Mater. 2002, 14, 463.

[18] M. Redecker, D. D. C. Bradley, M. Inbasekaran, E. P. Woo, Appl. Phys. Lett. 1998, 73, 1565.

[19] M. Belletête, M. Ranger, S. Beaupré, M. Leclerc, G. Durocher, Chem. Phys. Lett. 2000, 316, 101

[20] S. Setayesh, A. C. Grimsdale, T. Weil, V. Enkelmann, K. Müllen, F. Meghdadi, E. J. W. List, G. Leising, J. Am. Chem. Soc. 2001, 123, 946.

[21] K.-T. Wong, Y.-Y. Chien, R.-T. Chen, C.-F. Wang, Y.-T. Lin, H.-H. Chiang, P.-Y. Hsieh, C.-C. Wu, C. H. Chou, Y. O. Su, G.-H. Lee, S.-M. Peng, J. Am. Chem. Soc. 2002, 124, 11576.

[22] C.-C. Wu, T.-L. Liu, W.-Y. Hung, Y.-T. Lin, K.-T. Wong, R.-T. Chen, Y.-M. Chen, Y.-Y. Chien, J. Am. Chem. Soc. 2003, 125, 3710.

[23] Y. Kuwabara, H. Ogawa, H. Inada, N. Noma, Y. Shirota, Adv. Mater. 1994, 6, 677 .

[24] J. Shi, C. W. Tang, C. H. Chen, US Patent 5 646948, 1997.
[25] L. S. Hung, C. W. Tang, M. G. Mason, Appl. Phys. Lett. 1997, 70, 152.

[26] A. Elscher, F. Bruder, H.-W. Heuer, F. Jonas, A. Karbach, S. Kirchmeyer, S. Thurm, R. Wehrmann, Synth. Met. 2000, 111, 139.

[27] V. Choong, Y. Park, Y Gao, T. Wehrmeister, K. Müllen, B. R. Hsieh, C. W. Tang, Appl. Phys. Lett. 1996, 69, 1492

[28] U. Lemmer, S. Karg, M. Scheidler, M. Deussen, W. Ries, B. Cleve, P. Thomas, H. Bässler, M. Schwoerer, E. O. Göbel, Synth. Met. 1994, $67,169$.

[29] R. Kersting, U. Lemmer, M. Deussen, H. J. Bakker, R. F. Mahrt, H. Kurz, V. I. Arkhipov, H. Bässler, E. O. Göbel, Phys. Rev. Lett. 1994, 73, 1440.

[30] C. Adachi, T. Tsutsui, S. Saito, Appl. Phys. Lett. 1990, 57, 531.

[31] L.-H. Chan, R.-H. Lee, C.-F. Hsieh, H.-C. Yeh, C.-T. Chen, J. Am. Chem. Soc. 2002, 124, 6469.

[32] T. Sano, Y. Hamada, K. Shibata, IEEE J. Sel. Top. Quantum Electron. 1998, 4, 34.

[33] H. Kirihata, M. Uda, Rev. Sci. Instrum. 1981, 52, 68.

[34] C.-C. Wu, W.-Y. Hung, T.-L. Liu, L.-Z. Zhang, T.-Y. Luh, J. Appl. Phys. 2003, 93, 5465.

\section{Self-Assembled $\operatorname{In}_{2} \mathrm{O}_{3}$ Nanocrystal Chains and Nanowire Networks**}

\author{
By Jingyu Lao, Jianyu Huang, Dezhi Wang, \\ and Zhifeng Ren*
}

The fabrication of one-dimensional nanowires has attracted great attention because of their contribution to the understanding of novel physical properties and potential applications in nanoelectronic and optoelectronic devices. ${ }^{[1,2]} \mathrm{Re}$ cently, much attention has been paid to the fabrication of nanostructures of wide-bandgap transparent semiconducting oxides $^{[3,4]}$ because of their interesting optical and electronic properties. Among them, $\mathrm{In}_{2} \mathrm{O}_{3}$ has a direct bandgap of around $3.6 \mathrm{eV}$ and has been used in windows that absorb sunlight and turn the energy into heat, solar cells, ${ }^{[5]}$ organic lightemitting diodes, ${ }^{[6]}$ and gas sensors. ${ }^{[7]}$ Hence, there are many reports on the synthesis of $\operatorname{In}_{2} \mathrm{O}_{3}$ nanostructures such as nanowires, ${ }^{\left[{ }^{[-12]}\right.}$ nanobelts, ${ }^{[3]}$ and single-crystal nanotubes filled with In. ${ }^{[13]} \mathrm{An} \mathrm{In}_{2} \mathrm{O}_{3}$ field-effect transistor ${ }^{[14]}$ with very high sensitivity ${ }^{[15]}$ to toxic gases such as $\mathrm{NH}_{3}$ and $\mathrm{NO}_{2}$ has also been fabricated. Here we report the synthesis and characterization of self-assembled networks made of $\operatorname{In}_{2} \mathrm{O}_{3}$ nanocrystal chains and nanowires by a vapor transport and condensation process.

[*] Prof. Z. F. Ren, Dr. J. Y. Lao, ${ }^{[+]}$Dr. J. Y. Huang, D. Z. Wang Department of Physics, Boston College Chestnut Hill, MA 02467 (USA) E-mail: renzh@bc.edu

[+] Present address: Emerging Technology Laboratory, GE Global Research, One Research Circle, Niskayuna, NY 12309, USA.

[**] The authors would like to thank Dr. W. Z. Li for the helpful discussions. This work is supported partly by The US Army Natick Soldier System Center under grants DAAD16-03-C-0052 and DAAD16-00-C9227, partly by DOE under a grant DE-FG02-00ER45805, and partly by the NSF under a grant CMS-0219836. Supporting information for this article is available online at Wiley InterScience or from the author. 